\title{
CFD modelling approach for dam break flow studies
}

\author{
C. Biscarini ${ }^{1,3}$, S. Di Francesco ${ }^{2,3}$, and P. Manciola ${ }^{2}$ \\ ${ }^{1}$ Water Resources Research And Documentation Centre, University For Foreigners, Villa La Colombella 0634 Perugia, Italy \\ ${ }^{2}$ Department of Civil and Environmental Engineering, University of Perugia, Via G. Duranti 9306125 Perugia, Italy \\ ${ }^{3} \mathrm{H}^{2} \mathrm{CU}$, Honors Center of Italian Universities, University of Rome La Sapienza, Rome, Italy
}

Received: 5 October 2009 - Published in Hydrol. Earth Syst. Sci. Discuss.: 3 November 2009

Revised: 15 April 2010 - Accepted: 16 April 2010 - Published: 27 April 2010

\begin{abstract}
This paper presents numerical simulations of free surface flows induced by a dam break comparing the shallow water approach to fully three-dimensional simulations. The latter are based on the solution of the complete set of Reynolds-Averaged Navier-Stokes (RANS) equations coupled to the Volume of Fluid (VOF) method.

The methods assessment and comparison are carried out on a dam break over a flat bed without friction, a dam break over a triangular bottom sill and a dam break flow over a $90^{\circ}$ bend. Experimental and numerical literature data are compared to present results.

The results demonstrate that the shallow water approach, even if able to sufficiently reproduce the main aspects of the fluid flows, loses some three-dimensional phenomena, due to the incorrect shallow water idealization that neglects the three-dimensional aspects related to the gravity force.
\end{abstract}

\section{Introduction}

A dam break is the partial or catastrophic failure of a dam which leads to an uncontrolled release of water (Fread, 1993). The potential catastrophic failure and the resultant downstream flood damage is a scenario that is of great concern.

The mitigation of the impacts to the greatest possible degree requires modelling of the flood with sufficient detail so as to capture both the spatial and temporal evolutions of the flood event (Jorgenson, 2004), as well of the velocity field. The selection of an appropriate model to correctly simulate dambreak flood routing is therefore an essential step.

Traditionally, one and two-dimensional models have been used to model dam break flooding, but these models are lim-

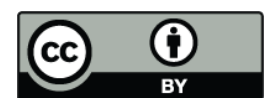

Correspondence to: C. Biscarini (biscarini.chiara@unistrapg.it) ited in their ability to capture the flood spatial extent, in terms of flow depth and velocity and timing of flood arrival and recession, with any degree of detail.

The development in the last years has led to several numerical models aimed at solving the so-called dam break problem (Soarez Frazao, 2002).

The Concerted Action on Dam Break Modelling (CADAM) project (Morris,1998), has been set in motion by the European Union to investigate current methods and use in simulating and predicting the effects of dam failures. The obtained results show that shallow water scheme is reasonably suitable for the representation of free surface sharp transient (Wang et al., 2000) and the authors concluded that shallow water methods agree satisfactorily with experimental results (Alcrudo, 1998). Other examples of successful representation of dam-break flows with the shallow water approach are available in literature (Xanthopoulos et al., 1976; Hromadka et al., 1985; Fraccarollo and Toro, 1995; Aricò et al., 2007).

However, in some cases, these mathematical models and numerical solvers do not seem adequate to simulate some observed hydraulic aspects, particularly in the near-field.. The three-dimensional numerical simulations performed by Manciola et al. (1994) and De Maio et al. (2004) show that the SW approach may underestimate the wave front celerity and may fail in correctly reproducing water depth profiles. In the short time step immediately after the gate collapse, in fact, the flow is mainly influenced by vertical acceleration due to gravity and gradually-varied flow hypothesis does not hold.

However, this could may not be always the case, as noted by Tossou (2009) who compares Serre and SW equations and show that non hydrostatic terms slow down the flood wave.

The advent of extremely more powerful resources is paving the way to the use of Computational Fluid Dynamics (CFD) in an increasing number of scientific and engineering disciplines, including hydraulics and specifically flooding. Several three-dimensional CFD models, based on the complete set of the Navier Stokes equations, have been already

Published by Copernicus Publications on behalf of the European Geosciences Union. 
applied to typical hydraulic engineering cases, as flow over weirs, landslide generated waves, through bridge piers and dam breaks (Gómez-Gesteira and Dalrymple, 2004; Nagata, 2005; Quecedo et al., 2005; Liang et al., 2007; Mohammadi. 2008; Biscarini, 2009).

To validate numerical simulations of flooding waves and to investigate current methods and their use in simulating and predicting the effects of dam failures, the CADAM has defined a set of analytical and experimental benchmarks. In the present paper the validation proposed by CADAM is applied and three test cases are considered:

- a dam break over a dry bed without friction (Fennema and Chaundry, 1990);

- a dam break over a triangular bottom sill (Soarez, 2002);

- dam break flow over a $90^{\circ}$ bend (Soarez Frazão and Zech, 2002).

We compare the experimental data with the modelling results deriving from a shallow water and a detailed Navier-Stokes numerical models. The former is based on two-dimensional hydrodynamics and sediment transport model for unsteady open channel flows and the latter on the Reynolds-Averaged Navier-Stokes (RANS) algorithm. In the latter, the water-air interface is captured with the volume of fluid (VOF) method, designed for two or more immiscible fluids where only one fluid (i.e. air) is compressible and the position of the interface between the fluids is of interest. Therefore it is perfectly suitable for describing free-surface problems.

In all the performed test cases, friction effects are neglected. In fact, even if frictionless simulations are not realistic, the present paper is focused on highlighting the performances of hydraulic numerical methods on typical simplified test cases.

\section{Numerical modelling}

Using an Eulerian approach, the description of fluid motion requires that the thermodynamic state be determined in terms of sensible fluid properties, pressure, $P$, density, $\rho$ and temperature, $T$, and of the velocity field $u(x, y)$ (Hirsch, 1992; Abbott and Basco, 1989; Patankar, 1981). Therefore, in a three-dimensional space for a given fluid system having two intensive degrees of freedom, we have six independent variables as unknowns, thus requiring six independent equations. The six equations (Navier-Stokes equations) are given by the equation of state and the three fundamental principles of conservation: mass continuity, Newton 2nd law or momentum conservation that leads to the well known Navier-Stokes system of equations (three equations in a three-dimensional space $x, y$ and $z$ ) and energy conservation (1st law of thermodynamics). For the majority of hydraulic applications involving water flow, however, the liquid flow is considered isothermal and incompressible.
The above system of equations, however, is valid for one phase, while in hydraulic flows at least two phases are always present, water and air. The task of simulating the behaviour of multi-phase flows is very challenging, due to the inherent complexity of the involved phenomena (i.e. moving interfaces with complex topology), and represents one of the leading edges of computational physics.

Among the different approaches available in literature to track the water-air interface in hydraulic problems, in this paper we compare the detailed NS model coupled to the VOF approximation with the simplified shallow water model that, as a matter of fact, leaves the multiphase nature of hydraulic flows by simulating the fluid dynamics in two dimensions and assuming a simplified approach for the water elevation dimension.

\subsection{Turbulence modelling}

In principle, Navier-Stokes equation can be used to simulate both laminar and turbulent flows without averaging or approximations other than the necessary numerical discretisations. However, turbulent flows at realistic Reynolds numbers span a large range of turbulent length and time scales and in a Direct Numerical Simulation (DNS) the discretisation of the domain should capture all of the kinetic energy dissipation, thus involving length scales that would require a prohibitively fine mesh for practical engineering problems (the total cost of a direct simulation is proportional to $R e^{3}$ ).

A large amount of CFD research has concentrated on methods which make use of turbulence models to predict the effects of turbulence in fluid flows without resolving all scales of the smallest turbulent fluctuations. There are two main groups of turbulence models:

- the introduction of averaged and fluctuating quantities that modify the unsteady Navier-Stokes into the Reynolds Averaged Navier-Stokes (RANS) equations (Rodi, 1979);

- Large Eddy Simulation (LES) (Galperin, 1993) approach based on the filtering of the flow field by directly simulating the large-scale structures (resolved grid scales), which are responsible for most of the transport of mass and momentum, and somehow modelling the small-scale structures (unresolved sub-grid scales), the contribution of which to momentum transport is little.

Due to the higher computational effort required by the latter approach, often used as an intermediate technique between the DNS of turbulent flows and the resolution of RANS equations, in this paper the $k-\varepsilon$ model is used in both the shallow water approximation and the detailed three-dimensional simulation. In particular, the depth-integrated version is used for the SW while standard version is employed for the 3-D NSVOF. 


\subsection{Two-dimensional Shallow Water Numerical model}

The shallow water model (Faber, 1995) approximation is based on the hypothesis that a layer of water flows over a horizontal, flat surface with elevation $Z(x, y, t)$. This means that the pressure distribution along each vertical is hydrostatic. If we assume that the horizontal scale of flow features is large compared to the depth of the water, the flow velocity is independent of depth (i.e. $\boldsymbol{u}=\boldsymbol{u}(x, y, t))$ and that the water within the layer is in hydrostatic balance, the model equations become:

Continuity equation:

$$
\frac{\partial Z}{\partial t}+\frac{\partial(h u)}{\partial t}+\frac{\partial(h v)}{\partial t}=0
$$

Momentum equations :

$$
\begin{aligned}
& \frac{\partial u}{\partial t}+\boldsymbol{u} \frac{\partial u}{\partial x}+\boldsymbol{v} \frac{\partial u}{\partial y}=-\boldsymbol{g} \frac{\partial Z}{\partial x}+\frac{1}{h}\left[\frac{\partial\left(h \tau_{x x}\right)}{\partial x}+\frac{\partial\left(h \tau_{y x}\right)}{\partial y}\right]-\frac{\tau_{b x}}{\rho h}+f_{\text {Cor }} \boldsymbol{v} \\
& \frac{\partial v}{\partial t}+\boldsymbol{u} \frac{\partial v}{\partial x}+\boldsymbol{v} \frac{\partial v}{\partial y}=-\boldsymbol{g} \frac{\partial Z}{\partial y}+\frac{1}{h}\left[\frac{\partial\left(h \tau_{y x}\right)}{\partial x}+\frac{\partial\left(h \tau_{y y}\right)}{\partial y}\right]-\frac{\tau_{b y}}{\rho h}+f_{\text {Cor }} \boldsymbol{u}
\end{aligned}
$$

where $\boldsymbol{u}$ and $\boldsymbol{v}$ are the depth-integrated velocity components in the $x$ and $y$ directions, respectively, $g$ is the gravitational acceleration, $Z$ is the water surface elevation, $\rho$ is water density, $h$ is the local water depth, $f_{\text {Cor }}$ is the Coriolis parameter; $\tau_{y x}, \tau_{x x}, \tau_{y y}$, are the depth integrated Reynolds stresses; and $\tau_{b x}$ and $\tau_{b y}$ are the shear stresses on the bed surface.

The above system of equations basically results from a depth averaging procedure of the Navier-Stokes equations and is usually called depth integrated two-dimensional Navier-Stokes equations (or Shallow Water model). As a matter of fact, the shallow water model is a single phase model, as only the water flow field in the plane $x-y$ is solved.

\subsection{Numerical scheme for the shallow water approach}

In this paper, the shallow water approach is tested by using the open-source CCHE2-D code (Jia, 1999), which has been extensively applied to simulate a variety of free surface flow and sediment transport related phenomena (Jia, 2001). Boussineq's theory (Boussinesq, 1903) is used to approximate turbulent shear stresses and the depth integrated version of the $k-\varepsilon$ model is employed to simulate the two test cases.

The set of SW equations is solved implicitly using the control volume approach and the efficient element method (Wang, 1992). The continuity equation for surface elevation is solved on a structured grid with quadrilateral elements. At each node an element is formed using the surrounding eight nodes making a total of nine nodes working element.

\subsection{Three-dimensional multiphase model}

As already discussed above, the derivation of the Shallow Water equations is based on the assumption that vertical velocities and accelerations are negligible. This results into a hydrostatic pressure distribution. However, when high free surface gradients exist, such as those at the failure site during the first instants, or when physical obstacles or steep changes on the bed slope are encountered by the flood wave, this assumption is no longer valid. Therefore, non-simplified models are needed to accurately solve the three-dimensional structure of the flow in these areas (Fraccarolllo and Toro, 1995; Mohapatra et al., 1999).

The three-dimensional multiphase approach proposed here is based on the numerical resolution of the incompressible RANS equations. To maintain the multiphase nature of the flow, there are currently two approaches widely used: the Euler-Lagrange approach and the Euler-Euler approach. In the latter approach, the different phase is taken into account by considering that the volume of a phase cannot be occupied by other phases. Then the concept of phase volume fractions as continuous functions of space and time is introduced.

In this paper, the so-called Volume Of Fluid (VOF) method is used. The VOF method is a surface-tracking technique applied to a fixed Eulerian mesh, in which a species transport equation is used to determine the relative volume fraction of the two phases, or phase fraction, in each computational cell. Practically, a single set of RANS equations is solved and shared by the fluids and for the additional phase, its volume fraction $\gamma$ is tracked throughout the domain.

Therefore, the full set of governing equations for the fluid flow are:

$\nabla \cdot \boldsymbol{u}=0$

$\frac{\partial \rho \boldsymbol{u}}{\partial t}+\nabla \cdot(\rho \boldsymbol{u} \boldsymbol{u})-\nabla \cdot\left(\left(\mu+\mu_{t}\right) s\right)=-\nabla p+\rho \boldsymbol{g}+\sigma K \frac{\nabla \gamma}{|\nabla \gamma|}$

$\frac{\partial \gamma}{\partial t}+\nabla \cdot(\boldsymbol{u} \gamma)=0$

where $p$ is the pressure field, $\mu_{t}$ is the turbulent eddy viscosity, $S$ is the strain rate tensor defined by $s=\frac{1}{2}\left(\nabla \boldsymbol{u}+\nabla \boldsymbol{u}^{T}\right), \sigma$ is the surface tension and $K$ is the surface curvature.

For the incompressible phase volume fraction, $\gamma$, the following three conditions are possible:

$-0<\gamma<1$ : when the infinitesimal volume contains the interface between the q-th fluid and one or more other fluids;

$-\gamma=0:$ volume occupied by air;

$-\gamma=1$ : volume occupied by water.

Therefore the interface between the species is not explicitly computed, but rather emerges as a property of the phase fraction field. Since the phase fraction can have any value between 0 and 1 , the interface is never sharply defined, but occupies a volume around the region where a sharp interface should exist. 
Physical properties are calculated as weighted averages based on this fraction. The density $\rho$ and viscosity $\mu$ in the domain are, therefore, calculated as follows:

$\rho=\gamma \rho_{1}+(1-\gamma) \rho_{2}$

$\mu=\gamma \mu_{1}+(1-\gamma) \mu_{2}$

where subscripts 1 and 2 refer to the gas and the liquid, respectively.

As numerical diffusion would spread out the sharp interface between water and air, a compressive interface capturing scheme is used to re-sharpen the interface. Details about the present free surface modelling algorithm and the CICSAM scheme can be found in Ubbink (1999).

\subsection{Numerical scheme for the three-dimensional approach}

The model used in this work is based on an open source computational fluid dynamics (CFD) platform named OpenFOAM (OpenCFD, 2008), freely available on the Internet. OpenFOAM, primarily designed for problems in continuum mechanics, uses the tensorial approach and object oriented techniques (Weller, 1998). It is an open source library (source files are in $\mathrm{C}++$ ) for solving partial differential equations and it allows customizing numerical solvers for continuum mechanics with particular emphasis on fluid dynamics.

In this work, the high resolution VOF method proposed by Ubbink (1999) is used to track the free surface. The CICSAM (Compressive Interface Capturing Scheme for Arbitrary Meshes) scheme treats the whole domain as the mixture of two liquids. Volume fraction of each liquid is used as the weighting factor to get the mixture properties, such as density and viscosity.

The numerical solution of the Navier-Stokes equation for incompressible fluid flow imposes two main problems (Jasak, 1996): the nonlinearity of the momentum equation and the pressure-velocity coupling. For the first problem, two common methods can be used. The first is to solve a nonlinear algebraic system after the discretization. This will entail a lot of computational effort. The other is to linearize the convection term in the momentum equation by using the fluid velocity in previous time steps which meets the divergencefree condition. The latter method is used in this research. For pressure-velocity coupling, many schemes exist, such as the semi- implicit method for pressure linked equation (SIMPLE) (Patankar, 1981) and pressure implicit splitting of operators (PISO) (Issa, 1986). PISO scheme is used in this code. For the $k-\varepsilon$ turbulence model equations, although $\mathrm{k}$ and $\varepsilon$ equations are coupled together, they are solved with a segregated approach, which means they are solved one at a time. This is the approach used in most CFD codes.

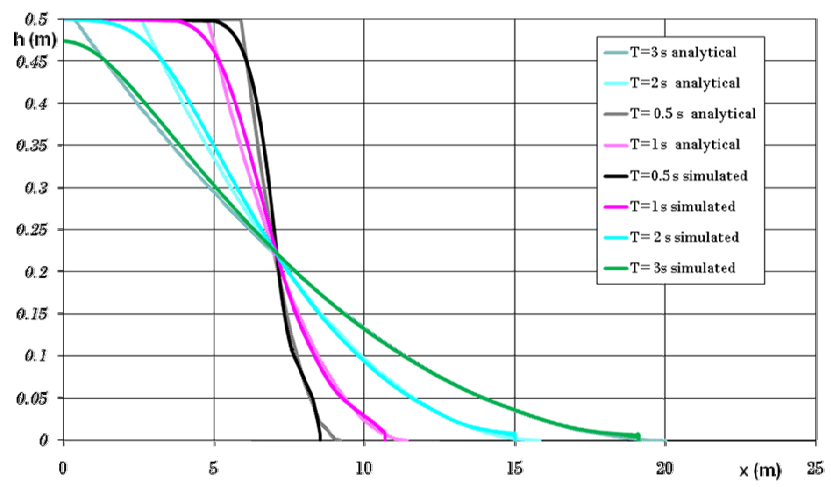

Fig. 1. Comparison between numerical and analytical data (Whitham, 1974) for a dam-break in a $20 \mathrm{~m}$-long straight channel.

\subsection{Comparison with an analytical solution}

In order to test the capability of the employed numerical model of performing transient simulations, a dam-break in a $20 \mathrm{~m}$-long straight channel has been modelled and the numerical results compared to the analytical solution provided by Whitham (1974). The numerical mesh is made up of 2000 cells with a grid-space of $0.01 \mathrm{~m}$. The bed is horizontal and the bottom and wall friction is set to 0 . At time zero, a $0.5 \mathrm{~m}$ high water volume on the 7 first meters of the channel is released instantaneously. A propagation wave moves downwards while a rarefaction wave goes back in the reservoir. Figure 1 shows the comparison between numerical and analytical data and highlights the capability of catching the front wave propagation.

\section{Validation}

The capabilities of the two models are here presented, comparing simulation results with analytical, numerical and experimental solutions available in literature:

1. dam break over a dry bed without friction (Fennema and Chaundry, 1990);

2. dam break over a triangular bottom sill (Soarez, 2002);

3. dam break flow over a $90^{\circ}$ bend (Soarez Frazão and Zech, 2002).

\subsection{Test case 1: partial instantaneous dam break over flat bed without friction}

The test consists of simulating the submersion wave due to the partial collapse of a dam. The spatial domain is a $200 \mathrm{~m} \times 200 \mathrm{~m}$ flat region, with a dam in the middle. At the beginning of the simulation the water surface level is set in $10 \mathrm{~m}$ for the upstream region and $5 \mathrm{~m}$ for the downstream 


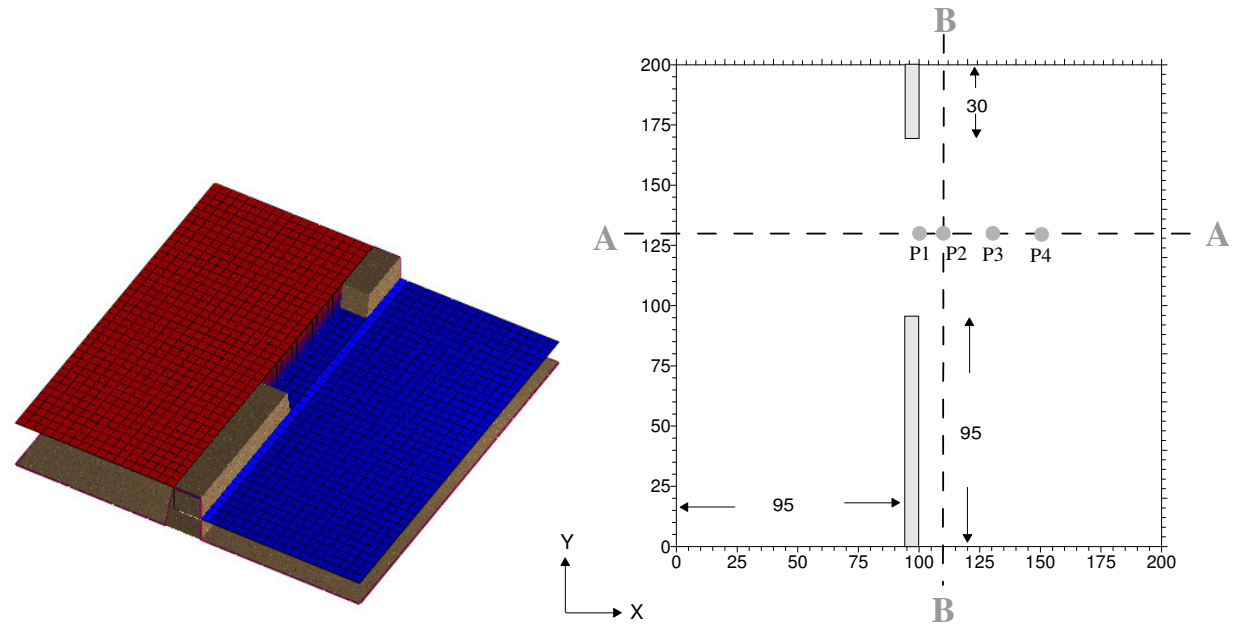

Fig. 2. Plan view (dimension in $\mathrm{m}$ ) - Geometric Schematization of dam break over flat bed without friction test case. In plan, Sections A-A B-B, Points P1(100,130), P2(110,130),P3(130,130), P4(150,130) are shown.

one and the unsteady flow is generated by the instantaneous collapse of an asymmetrical $75 \mathrm{~m}$ long portion of the barrier (Fig. 2). The bottom is flat and ground resistance to the motion is neglected.

Although no analytical or experimental reference solutions are available, this test case is usually considered a validation benchmark, as also reported in the CADAM project. In fact, it has been widely simulated in literature with the SW approach (Fennema and Chaundry, 1990; Alcrudo,1993) but never with a full NS approach. In this paper the numerical results of the two approaches are compared and the threedimensional effects, as well as their importance in terms of hydraulic design, are highlighted.

\subsubsection{Simulations setup}

\section{Shallow water numerical model}

The simulation with the shallow water model is carried out using a time step of $0.02 \mathrm{~s}$. A null flow rate in the inlet section is set as the initial condition. All the computational domain is limited by no-slip walls.

\section{Three-dimensional CFD numerical model}

The $200 \times 200 \times 20 \mathrm{~m}$ domain is discretised with a structure mesh made up of hexahedral blocks $5 \times 5 \times 1 \mathrm{~m}$ in size. The simulation has been performed at a fixed time step of 0.02 s (i.e. equal to the $\mathrm{SW}$ ), with a Courant number never exceeding0.3. The small time step is due to the fact that the surface-tracking algorithm is considerably more sensitive to the Courant number than in standard fluid flow calculations. The geometric reconstruction was made through parametric meshes with grading and curved edges (Open Foam, 2008).
The top boundary of the domain is the atmosphere and the total pressure is set to zero, all the others are set as wall, being the study case a closed box. The non-uniform initial condition for the phase fraction $\gamma$ is specified.

At wall surfaces (bed, flume walls, bump faces), no-slip boundary conditions are employed, that is to say $\boldsymbol{u}=0$ is set for velocity with zero normal gradient for pressure. Surface tension effects between wall and water-air interface are neglected. This is done by setting the static contact angle, $\theta \mathrm{w}=90^{\circ}$ and the velocity scaling function to 0 .

The top boundary of the domain is the atmosphere, where the total pressure is set to zero.

\subsubsection{Results}

The computed water surface profiles are compared to the numerical results computed by Fennema and Chaundry (1990), who employed a shallow water model solved with an implicit finite difference method.

The comparison of the computed water level $7.2 \mathrm{~s}$ after the breach, when the flow reached the left side of the tank, is shown in Fig. 2. As expected the surface shape deriving from the shallow water model is in good agreement with the one obtained by Fennema (Alcrudo,1993), except for a little delay in the front wave position. Some significant differences are instead observed with the full Navier-Stokes threedimensional model:

- water surface levels immediately upstream the gate are lower than those predicted by the shallow water, due to the gravity force (Figs. 3 and 4);

- the front position shows that wave celerity is greater and water levels downstream the gate are higher than those predicted by the shallow water (Figs. 3 and 4). 

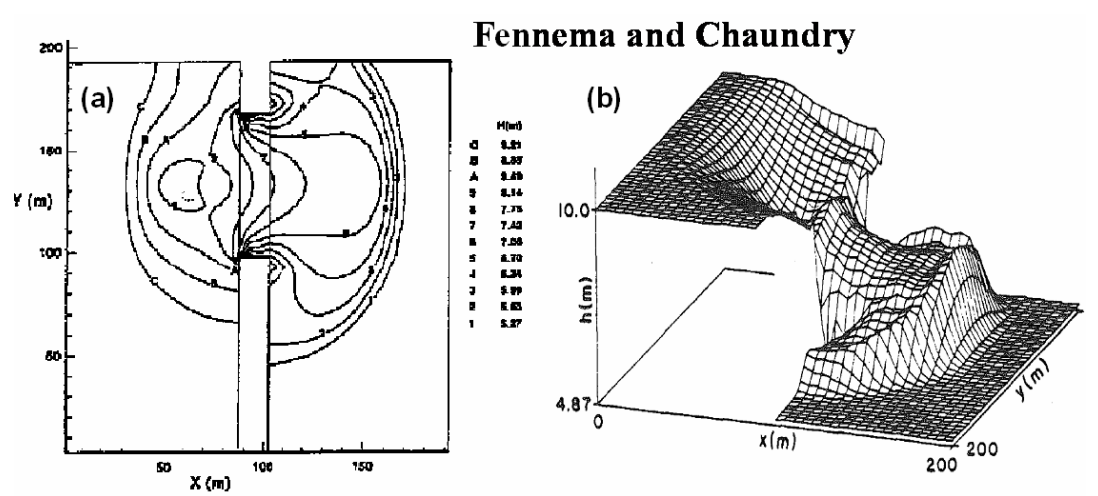

2D model
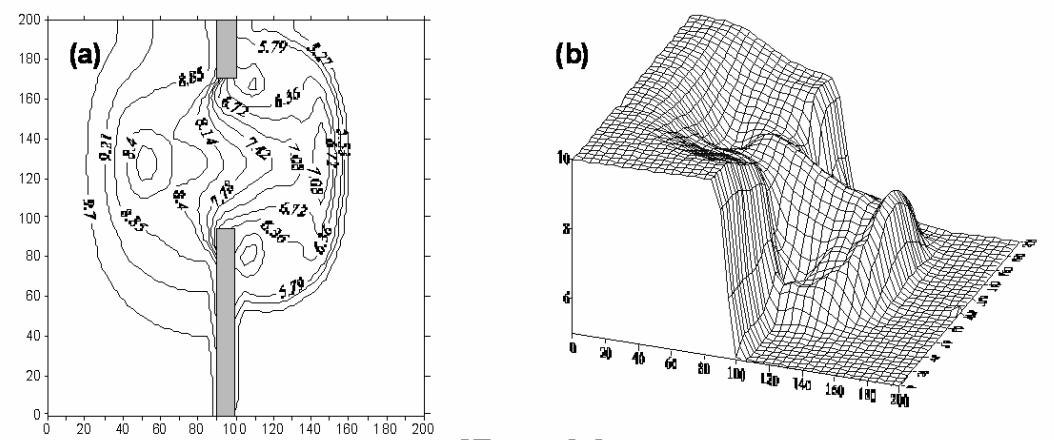

3D model
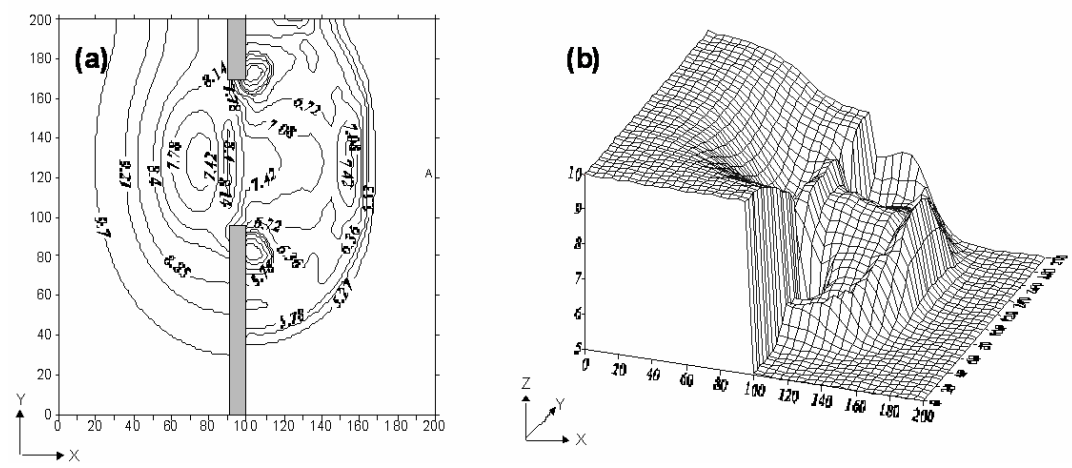

Fig. 3. Comparison between Fennema and Chaundry (1990), shallow water, full Navier Stokes simulations' results: (a) Contour levels at $5.2 \mathrm{~m}, 5.7 \mathrm{~m}, 6.2 \mathrm{~m}, 6.7 \mathrm{~m}, 7.2 \mathrm{~m}, 7.8 \mathrm{~m}, 8.2 \mathrm{~m}, 8.7 \mathrm{~m}, 9.2 \mathrm{~m}$ (b) Water surface wireframe (three-dimensional view) after $7.2 \mathrm{~s}$ from failure.

These results agree with the conclusions drawn by De Maio (2004), who observe that the shallow water model underestimates the front wave celerity and water depth profiles. This should be related to the three-dimensional aspects due to the gravity force, especially during the first time steps of the motion.

This behaviour is marked also in Fig. 5 where hydrographs at different monitor points are represented for both models.

The set of results originating from these simulations shows that the dam break problem is characterized by threedimensional aspects, that produce differences on water surface elevation and submersed wave travelling downstream.
The results demonstrated that 1-D models, or even 2-D, traditionally used in hydraulic engineering, are not adequate to simulate the generation and propagation of the bore immediately after the gate failure (Morris, 2000). Therefore, these simplified models could be coupled to detailed simulations of the dam break. Practically a detailed and a simplified one-dimensional model could be applied in cascade:

- simulation of the flood wave formation immediately after the collapse of the dam by means of a detailed model, in order to evaluate the discharge hydrograph;

- simulation of the propagation of this wave along the river by means of a hydraulic one-dimensional model (Werner, 2004). 

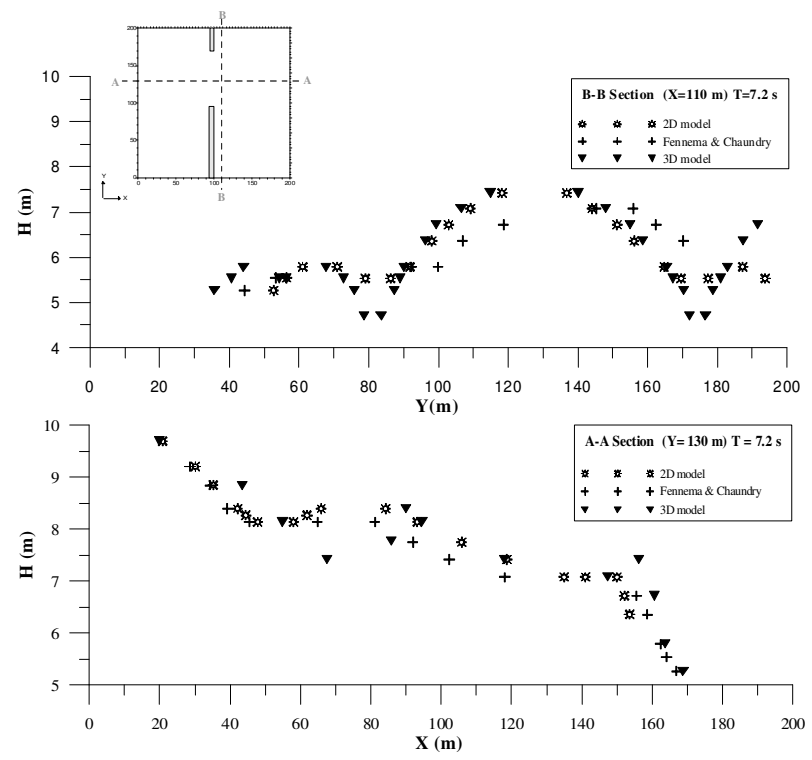

Fig. 4. Water depth at $7.2 \mathrm{~s}$ after the gate collapse: B-B and A-A sections.

In order to evaluate when (at what instant after failure) and where (at what downstream cross section) it is possible to switch from a detailed to a one-dimensional model with sufficient accuracy, we extended the downstream domain up to $1000 \mathrm{~m}$ from the gate. A relevant parameter for this kind of study could be the water surface variation along cross section, defined as $h_{c v}=\left(h_{\max }-h_{\min }\right) / h_{0}$.

Figure 6 shows water surface elevation and water surface variation along cross section at four different cross sections, located at a distance of $400 \mathrm{~m}, 500 \mathrm{~m}, 600 \mathrm{~m}$ and $700 \mathrm{~m}$ from the gate, during the first 100 seconds after failure. The parameter $\mathrm{h}_{c v}(t)$ could be used to establish a threshold value for the switch from detailed to simplified one-dimensional simulations. In other words, when the water surface variation along cross section is always lower than a certain value $\left(h_{c v}(t) \leq h_{c v, t} \forall t\right)$, the approximation of a one-dimensional simulation could be acceptable. Setting this threshold to 10\%, Fig. 7 highlights that a one-dimensional model could be used starting from a distance of $600 \mathrm{~m}$ from the gate (Section E-E).

Figures 7 and 8 show the difference in the water depth and the discharge hydrograph between the NS and the SW model at Section E-E. Two aspects are relevant:

- SW model underestimates the peak flow of about $30 \%$ with respect to NS.

- The peak arrival time predicted by the SW model is higher than the correspondent three-dimensional one of about $6 \mathrm{~s}$.

As far as computational efficiency is concerned, both SW and 3-D simulations have been performed in a PC with pro- cessor a AMD Phenom Quadcore $2.33 \mathrm{GHz}$ and $3.2 \mathrm{~Gb}$ of RAM memory. The SW model runs on Windows XP operative system, while the NS-VOF on Lynux Ubuntu 9.10 operative system. The simulation of the present test case took $0.25 \mathrm{~h}$ and $2 \mathrm{~h}$, for the 2-D model and the 3-D model, respectively. These data highlight that the computational effort of a full Navier-Stokes three-dimensional simulation, even if greater than that of the SW, is absolutely acceptable for the computer technology available today. On the other hand, the numbers above also highlight that the SW model may be one order of magnitude faster than the NS. This means that the SW approach is the ideal candidate for large computational domains, while the 3-D approach is more suitable for modeling smaller domains where the knowledge of the threedimensional structure of the flow is needed.

\subsection{Test case 2: dam break flow over a triangular obstacle}

The second test case is an experimental dam break over a triangular obstacle performed at the Université Catholique de Louvain (UCL), in the laboratory of the Civil Engineering Department (Soarez-Frazao, 2002).

The experimental setup (Fig. 9) consists of a closed rectangular channel $5.6 \mathrm{~m}$ long and $0.5 \mathrm{~m}$ wide, with glass walls. The upstream reservoir extends over $2.39 \mathrm{~m}$ and is initially filled with $0.111 \mathrm{~m}$ of water at rest. The gate separating the reservoir from the channel can be pulled up rapidly in order to simulate an instantaneous dam break. Downstream from the gate, there is a symmetrical bump 0.065 high with a bed slope of 0.014. Downstream from the bump, a pool contains $0.025 \mathrm{~m}$ of water. It is thus a closed system where water flows between the two reservoirs and is reflected against the bump and against the upstream and downstream walls.

High-speed CCD cameras were used to film the flow through the glass walls of the channel at a rate of 40 images per second. The experiments show a good reproducibility, allowing to combine the images obtained from different experiments to form a continuous water profile (Fig. 10).

This test is almost two-dimensional in the plane $x-z$, but it can perfectly highlight the differences between the shallow water and the three-dimensional approach. It is, in fact, twodimensional for the full Navier-Stokes model, but becomes one-dimensional for the shallow water model, as it neglects the elevation.

\subsubsection{Simulation setup}

\section{Two-dimensional shallow water numerical model}

The simulation was carried out using a spatial step of $0.05 \mathrm{~m}$ and a time step of $0.01 \mathrm{~s}$. The computational mesh consists of 11.113 nodes. Figure 11 reports the initial condition schematization. 

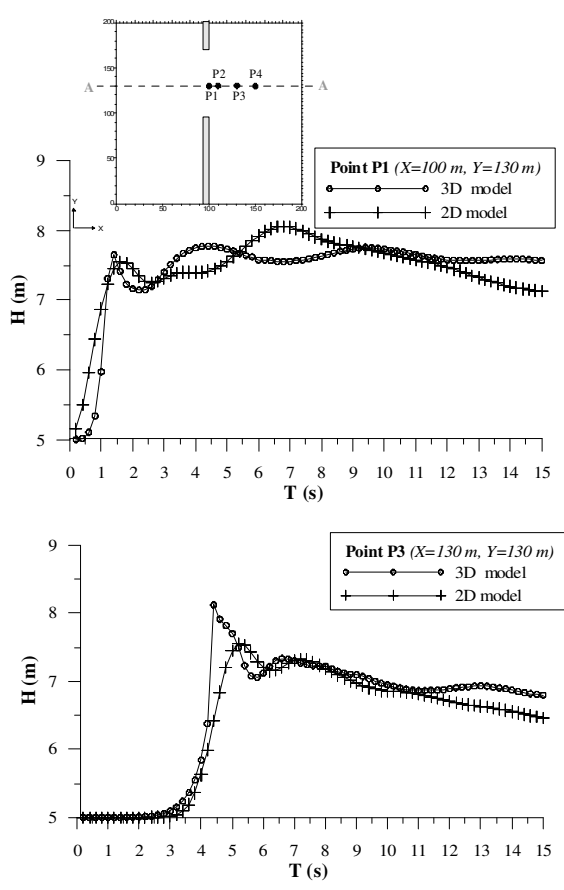

Fig. 5. Water level hydrograph at points P1, P2, P3, P4.

\section{Three-dimensional CFD numerical model}

The mesh geometry is composed by hexaedrons with $0.05 \mathrm{~m}$ side. The boundary patches are specified as wall and atmosphere. The simulation has been performed at a fixed time step of $0.01 \mathrm{~s}$ (i.e. equal to the SW), with a Courant number never exceeding 0.3 .

\subsubsection{Results}

The comparison between experimental and numerical results, with both models, is given in Fig. 13, in terms of free surface comparison at different times after the dam break.

During the collapse, the water impacts an obstacle at the bottom of the tank and creates a complicated flow structure, including several captured air pockets.

The comparison between simulated and experimental results, given in Fig. 12, clearly shows that the threedimensional model has the capability to represent the unsteady flow behaviour quite well. After the dam break, the water flows to the bump. Once it reaches this, a part of the wave is reflected and forms a negative bore travelling back in the upstream direction, while the other part moves up the obstacle (Fig. 12). At $t=1.8 \mathrm{~s}$ (Fig. 12a), the shallow water model is not capable of reproducing the real situation: the front wave is not in agreement with the experimental data. The three-dimensional model simulation results are quite similar to real behaviour.
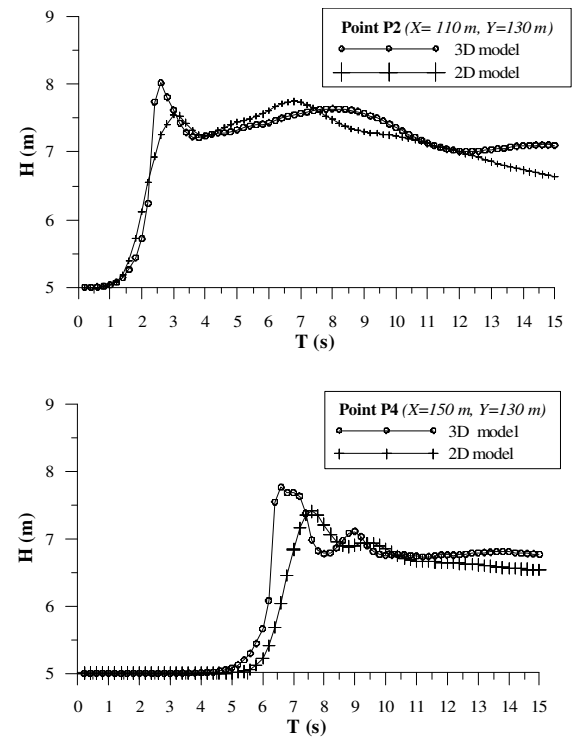

After passing the top of the bump, the water flows until it arrives in the second pool of water, where the front wave slows down and a positive bore forms (Fig. 12b, front-wave position $=5.2 \mathrm{~m}$ ). Again, the three-dimensional model results are in good agreement with the experimental data while the two-dimensional model is late.

At $t=3.7 \mathrm{~s}$ (Fig. 12c), the bore has reflected against the downstream wall and is travelling back to the bump, but the water is unable to pass the crest. This behaviour is well reproduced by both models.

After a second reflection against the downstream wall, the wave has passed the bump and is travelling back into the upstream direction. Significant differences between the shallow water results and the experimental results are observable also at $t=8.4 \mathrm{~s}$ (Fig. 12d).

Figure 13 finally shows that the flow picture frames captured at different times (top image at each time in Fig. 13) are all in good agreement with the numerical results (bottom image at each time in Fig. 13).

\subsection{Test case 4: dam break flow over a $90^{\circ}$ bend}

In dam-break phenomena the shape of the downstream valley assumes great importance. For instance, the presence of bends may slow down the front but may also cause an increase in the water level upstream or even lead to the formation of an upstream travelling bore. The second test case is an experimental dam break over a $90^{\circ}$ bend performed by Soarez Frazão and Zech (2002). 

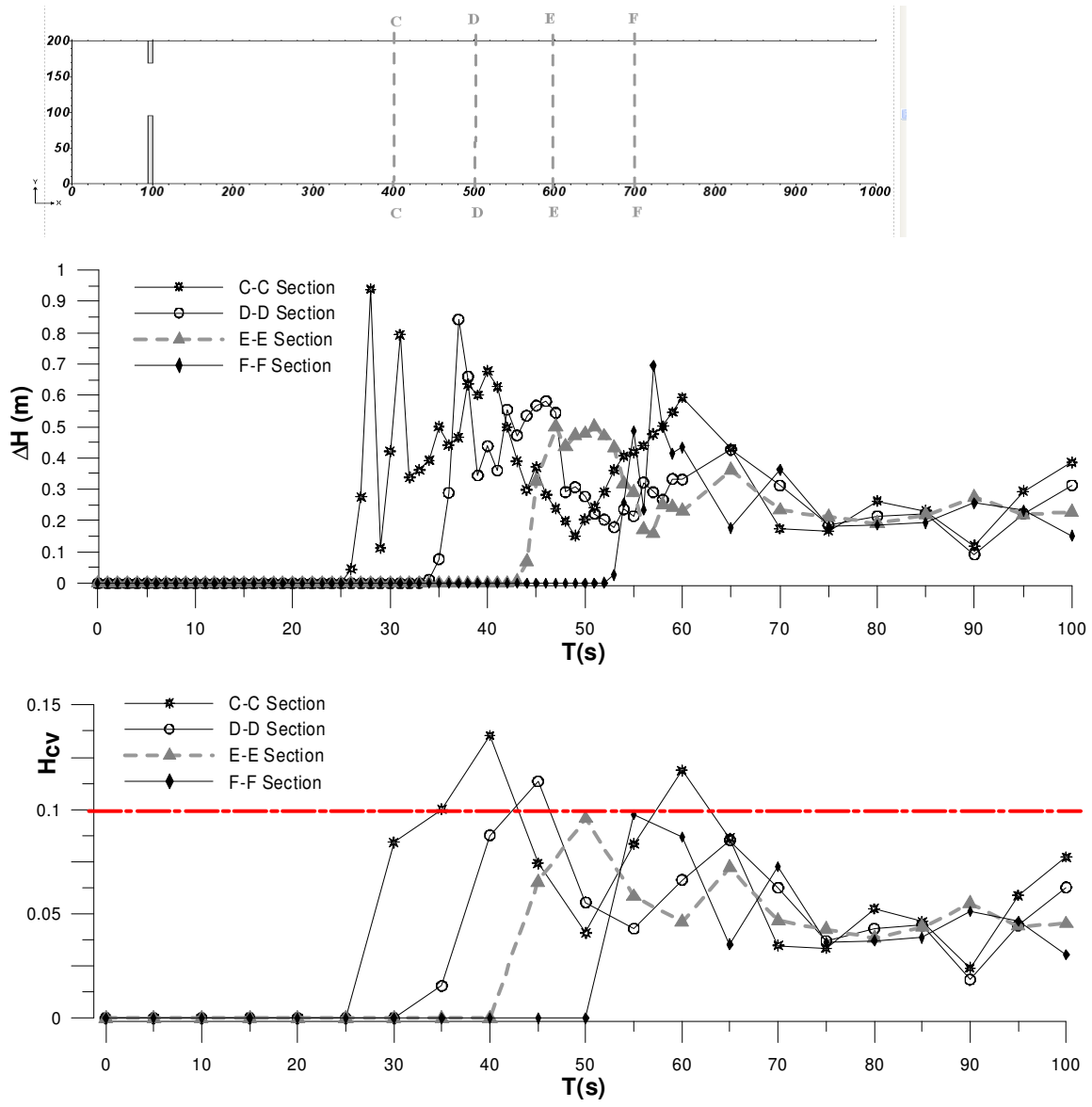

Fig. 6. $\Delta h$ and Hcv depending on time at different cross Section: $C-C(x=400), D-D(x=500), E-E(x=600), F-F(x=700)$.

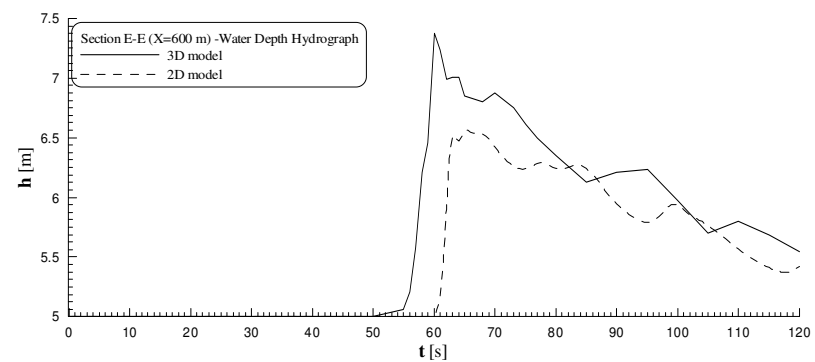

Fig. 7. Water Depth hydrograph at E-E Section $(x=600)$.

A $2.44 \cdot 2.39 \mathrm{~m}^{2}$ upstream reservoir is connected to a $0.495 \mathrm{~m}$ wide L-shaped rectangular channel with glass walls. The upstream reach is about $4 \mathrm{~m}$ long and the downstream reach, after the bend, is about $3 \mathrm{~m}$ long. The channel bed level is $0.33 \mathrm{~m}$ above the upstream reservoir bed level. The downstream end of the channel is open. The initial water level in the reservoir is $0.20 \mathrm{~m}$ above the channel bottom and the channel bed is initially dry. The experimental setup is shown in Fig. 14.

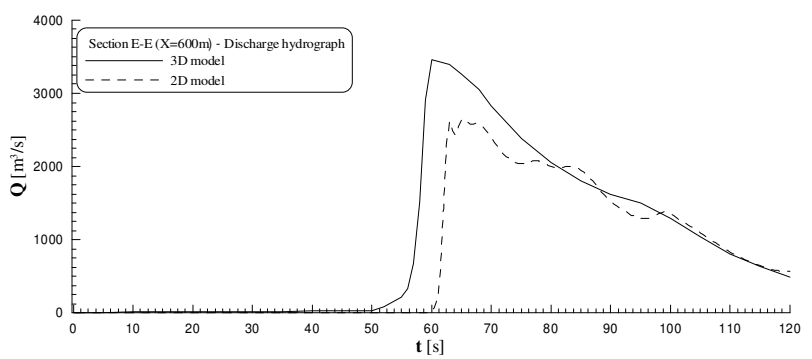

Fig. 8. Discharge hydrograph at E-E Section $(x=600)$.

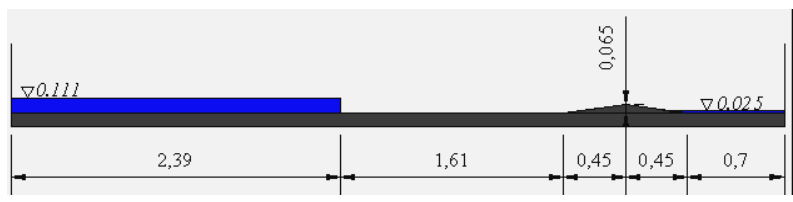

Fig. 9. Experimental set-up and initial conditions, all dimensions in $(\mathrm{m})$. 

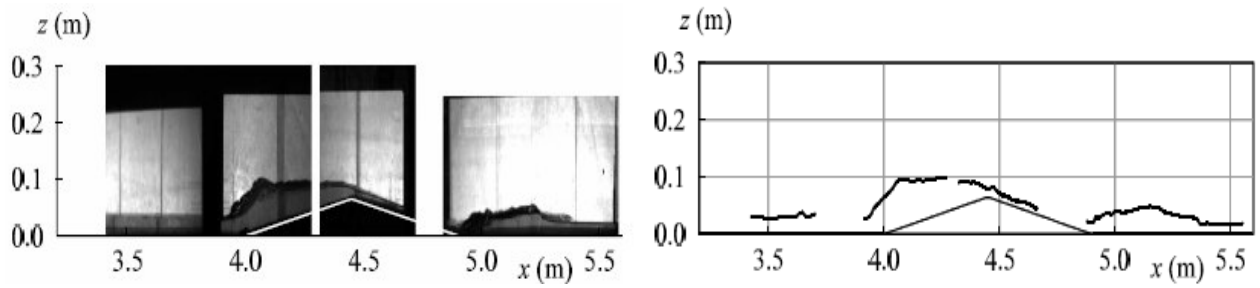

Fig. 10. Water surface at $1.8 \mathrm{~s}$ (Soarez et al., 2002): the position of the free surface is measured by an automatic recognition procedure to each filmed image.

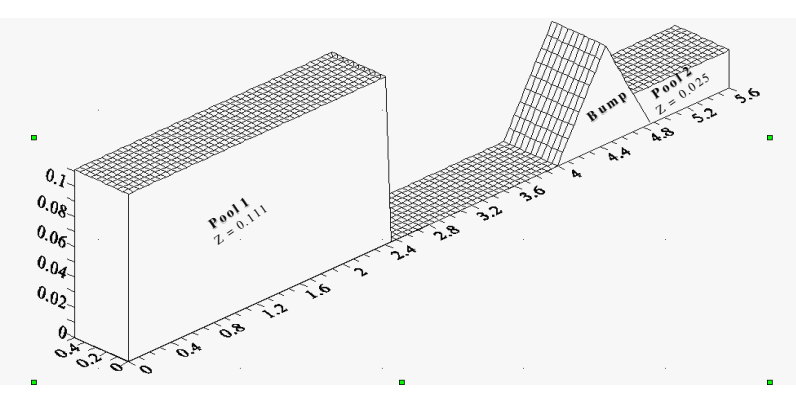

Fig. 11. Initial condition for the bump test case (Soarez et al., 2002).

The channel is equipped with a set of measurement devices, located at a fixed number of gauging points. Moreover, the water-level evolution was acquired by means of two high speed cameras placed next to the channel, at a frame rate of 40 images per second. The free-surface position is identified automatically on each frame.

\subsubsection{Simulation Setup}

\section{Two-dimensional shallow water numerical model}

The simulation was carried out using a spatial step of $0.01 \mathrm{~m}$ and a time step of $0.02 \mathrm{~s}$.

\section{Three-dimensional CFD numerical model}

The mesh geometry is composed by cubes with $0.01 \mathrm{~m}$ side. The boundary patches are specified as wall and atmosphere. For the open boundary the following conditions are applied: when the flow is going out of the domain, zero gradient condition is used, when the flow is entering the domain, a $1 \%$ turbulence intensity is used to specify $k$ and $\varepsilon$. The small amount of air turbulence will not affect the water flow field too much since water is much heavier than air (Liu and García, 2008). The simulation has been performed at a fixed time step of $0.02 \mathrm{~s}$, with a Courant number never exceeding 0.3 .
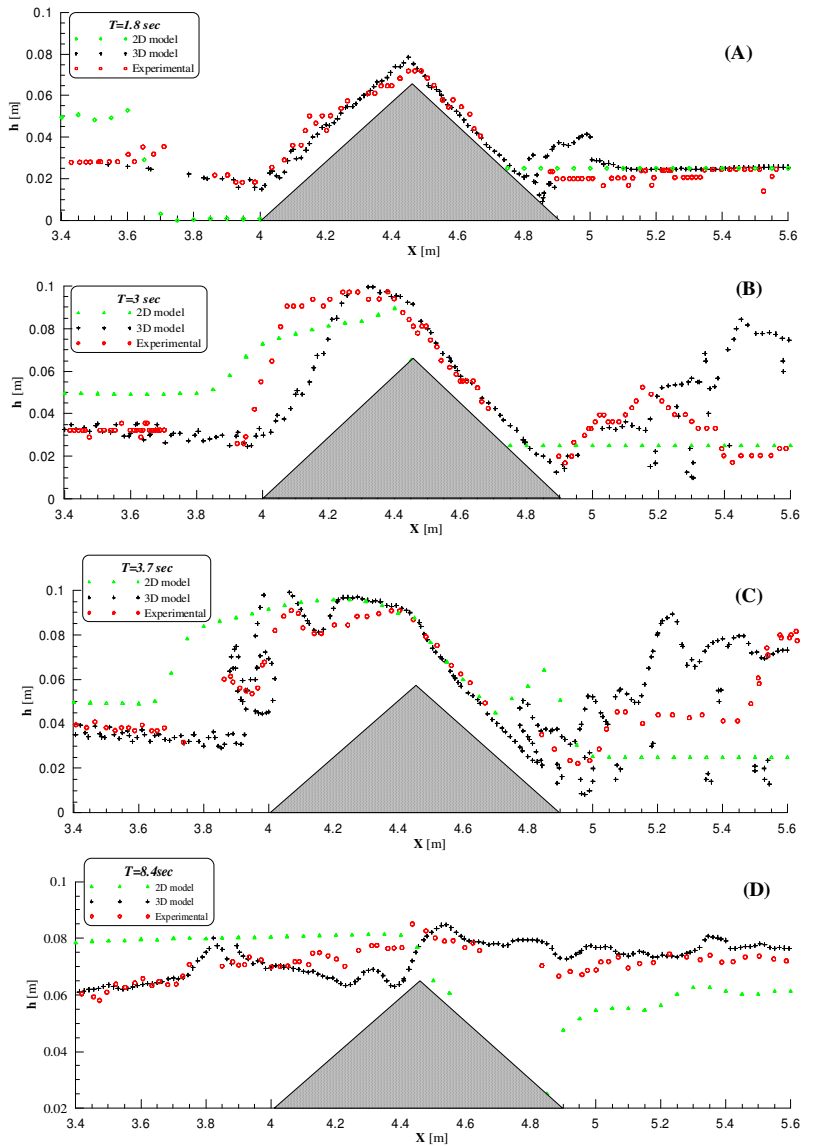

Fig. 12. Two-dimensional model, three-dimensional model, experimental water surface profile at $T=1.8 \mathrm{~s}$ (a) $T=3 \mathrm{~s}$ (b) $T=3.7 \mathrm{~s}$ (c), $T=8.4 \mathrm{~s}$.

\subsubsection{Results}

The computed and experimental free surface profiles are compared in Fig. 15 at different times and the overall agreement is satisfactory. When the gate is opened, the water flows rapidly into the channel and reaches the bend after approximately $3 \mathrm{~s}$ (Fig. 15a). There, the water reflects against the wall, a bore forms and begins to travel in the upstream direction, back to the reservoir. 

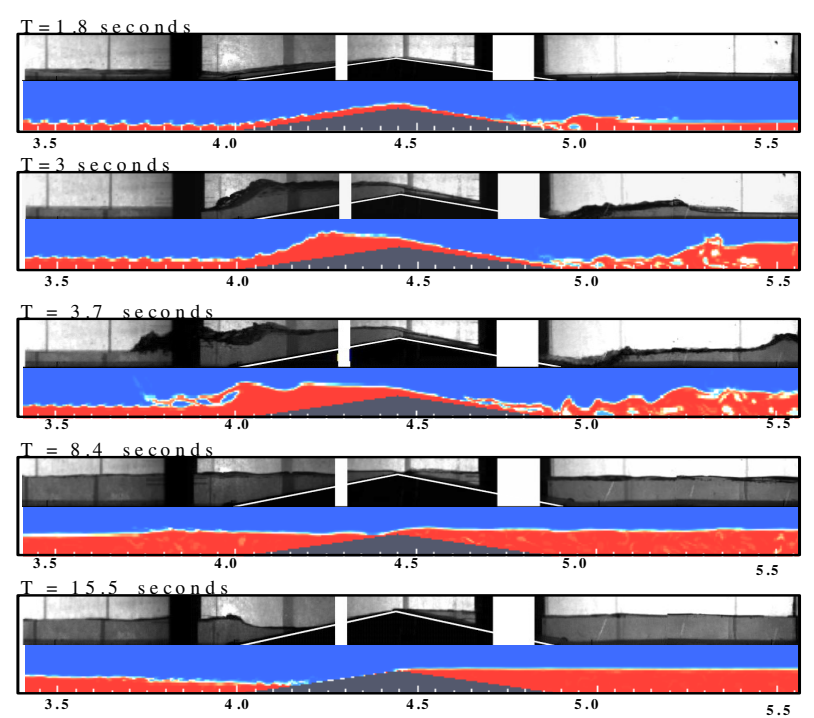

Fig. 13. Comparison between three-dimensional model results (bottom) and pictures of the experiment (top).

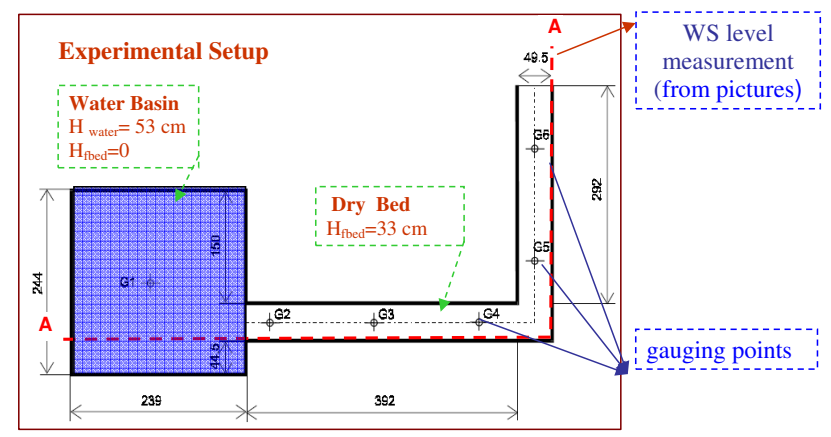

Fig. 14. Experimental set-up and initial conditions for the dam break over a $90^{\circ}$ bend test case, all dimensions in $\mathrm{cm}$. Gauging points G1, G2, G3, G4, G5 and G6 (Soarez et al., 2002.)

At $t=5 \mathrm{~s}$ the downstream front has almost reached the free end of the channel (Fig. 15b).

At $t=14 \mathrm{~s}$ the bore has almost reached the reservoir (Fig. 15d). After drowning in this, the flow becomes much slower, and attains an almost steady state, consisting in a progressive emptying of the reservoir.

The NS-VOF approach is able to correctly predict the wave reflection process, the water level, as well as, the formation of a bore travelling in the upstream direction. In Fig. 16 selected frames from the NS-VOF numerical simulation are reported. The important water level increase due to the reflection against the bend is well reproduced in the computation results. This effect is less evident in SW model results, where the bore travels slightly slower than the real one (Fig. 15).
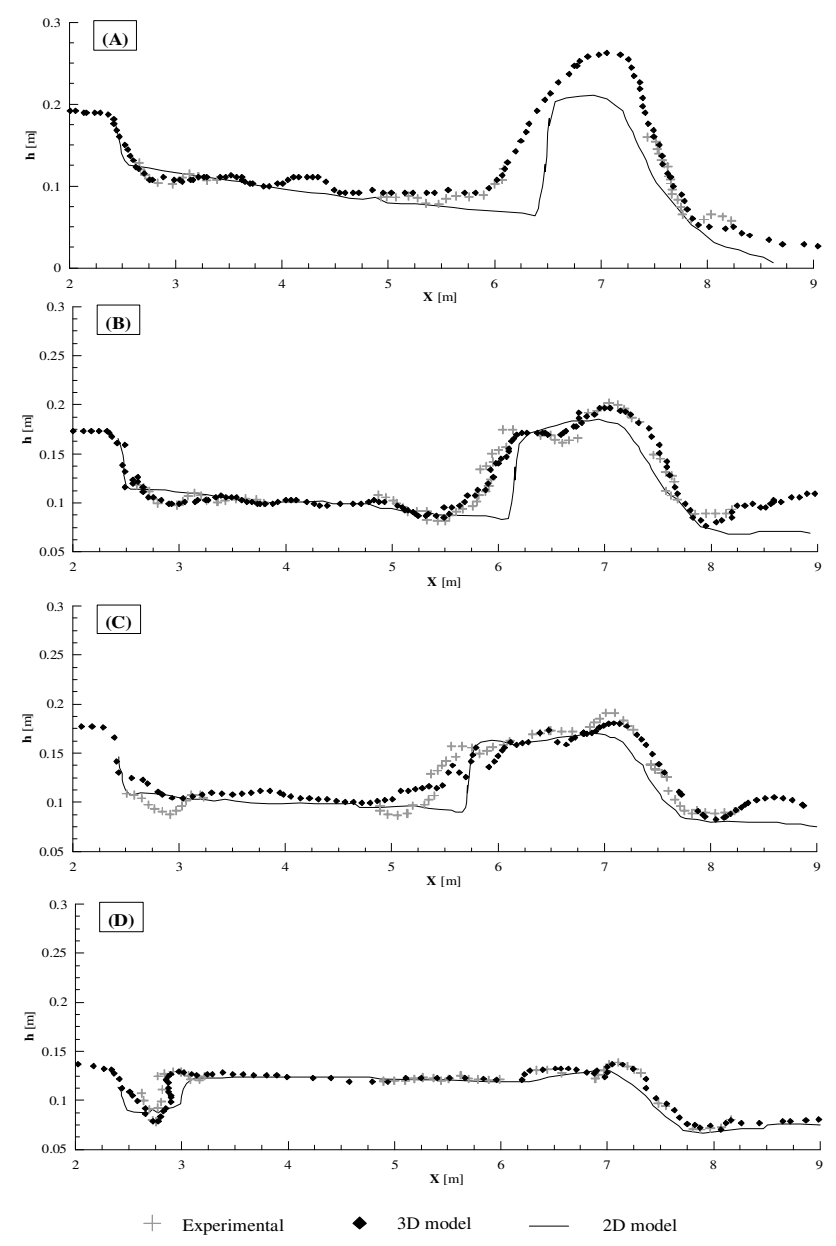

Fig. 15. Dam break over a $90^{\circ}$ bend test. Comparison between computed and experimental free surface profiles along section A-A' (outer bank) at different times after the failure: $3 \mathrm{~s}(\mathbf{A}), 5 \mathrm{~s} \mathrm{(B),} 7 \mathrm{~s}$ (C), 14 s (D).

However, also the SW model provides a good prediction of the phenomenon. The bore level is slightly underestimated, as also shown by Soarez et al. (2002) and the bore position is affected by an initial delay in the bore formation (Soarez et al., 2002).

\section{Conclusions}

The present paper addresses a relevant problem in hydraulic engineering: the selection of an appropriate model to undertake dam break flood routing.

The type of flow model may be classified according to the number of spatial dimensions they simulate the equations upon which their predictions are based and the numerical system applied to solve these equations during the simulation process. In the present paper, a SW and a RANS-VOF model have been tested on typical dam break flows. The capability 


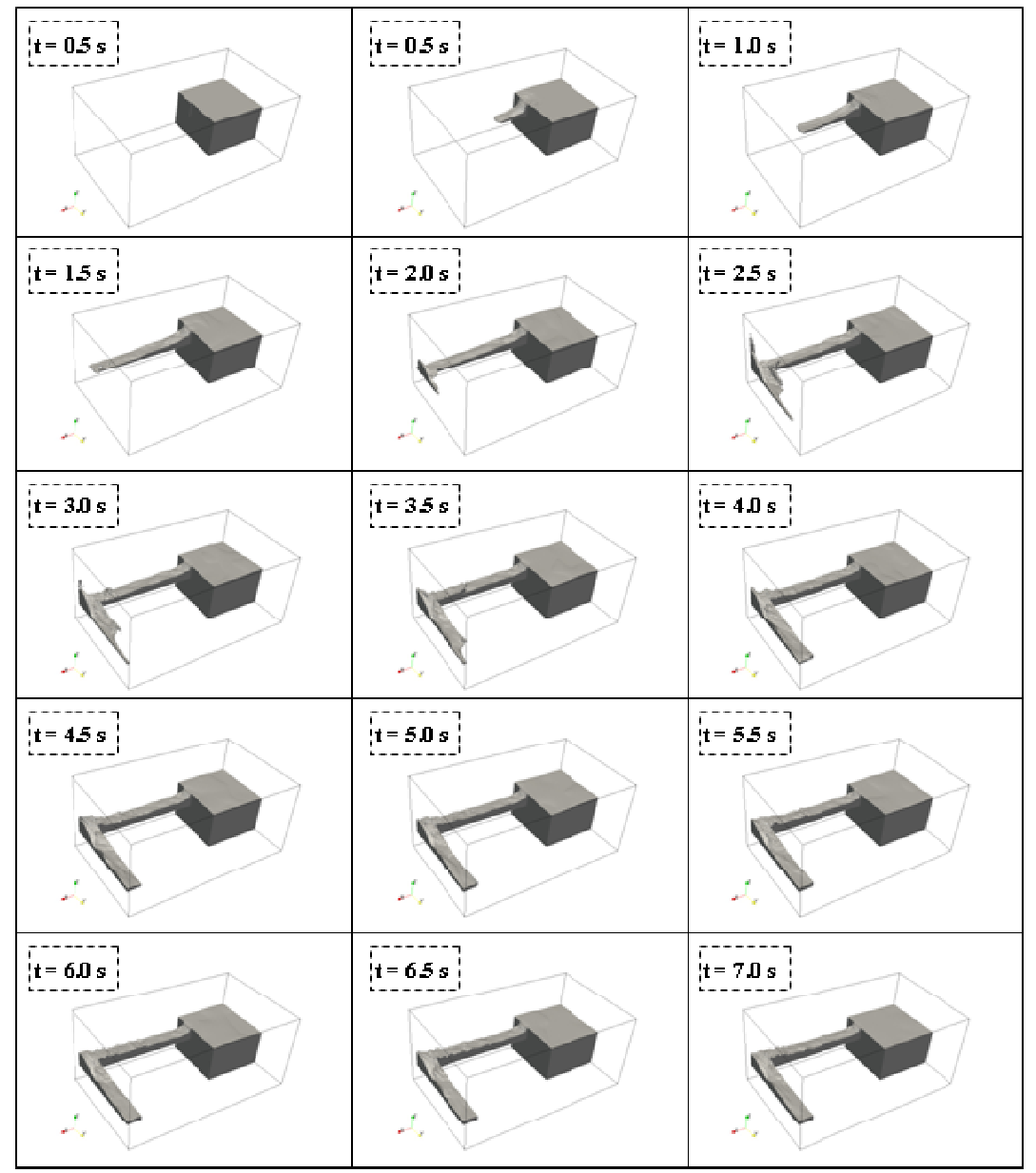

Fig. 16. Dam break over a $90^{\circ}$ bend test: selected frames from 3 -D model simulation.

of the RANS-VOF model to correctly simulate transient free surface simulations has been preliminary verified by comparing numerical results with the analytical solution of a dambreak in a $20 \mathrm{~m}$-long straight channel. Then the two models are compared for a dam break over a flat bed without friction. a dam break over a triangular bottom sill and a dam break flow over a $90^{\circ}$ bend.

As for the test case no analytical or experimental reference solutions are available, the observed differences between the two approaches are highlighted. In particular, the water surface levels predicted by the RANS-VOF simulations are lower immediately upstream the gate and higher downstream the gate with respect to those resulting from the SW simulations. Moreover, the peak arrival time predicted by the SW model is higher than the correspondent threedimensional one of about $6 \mathrm{~s}$. The differences are related to the three-dimensional effects of the gravity force, especially during the first time steps of the motion.
As far as computational efficiency is concerned, the duration of the RANS-VOF simulation is about one order of magnitude greater than that of the SW ( $2 \mathrm{~h}$ vs. $15 \mathrm{~min}$ ).

The comparison between simulated and experimental results, performed for the second test case and the third test cases, clearly shows that the three-dimensional model has the capability to represent the unsteady flow behaviour quite well in the whole observation period, while some differences between experimental data and numerical results from the shallow water model are observed. For the a dam break over a triangular bottom sill, it is observed that the SW underestimated the wave front celerity immediately after the gate collapse and do not reproduce the water depth profiles well. The SW simulation of the dam break flow over a $90^{\circ}$ bend is satisfactory, even if the wave front celerity is underestimated.

It is important to note that the aim of the paper is not to demonstrate the superiority of the three-dimensional approach for the solution of the dam break or dam breach problems, but to highlight the differences between the SW approach and the fully 3-D approach (with VOF). The advent of extremely powerful computational resources allows using 
three-dimensional models that could be effectively and efficiently applied in the near-field region and when the hypotheses behind the SW approach may lead to high errors. Furthermore, the three-dimensional model may provide a complete and detailed information on the physical quantities in space and time, that in turn give information on the potential flood evolution especially in terms of water depth, free surface profile, flow velocity, wave front dynamics etc. also over complicated terrain profiles and frequent discontinuities.

Edited by: E. Todini

\section{References}

Abbott, M. B. and Basco, D. R.: Computational fluid dynamics: An introduction for engineers, Harlow, Essex, England: Longman Scientific \& Technical, New York, NY, USA, Wiley, 439 pp., 1989.

Alcrudo, F. and Garcia-Navarro, P.: A high-resolution Godunovtype scheme in finite volumes for the two-dimensional shallowwater equations, Int. Journ. Num. Methods in Fluids, 16, 489$505,1993$.

Alcrudo, F. and Soares Frazão, S: Conclusions from 1st CADAM Meeting, Proc. of 1st CADAM Meeting, paper 5, Wallingford, 1998.

Aricò, C., Nasello, C., and Tucciarelli T.: A Marching in Space and Time (MAST) solver of the shallow water equations, Part II: the 2-D model, Adv. Water Res., 30(5), 1253-1271, 2007

Boussinesq, J.: Théorie analytique de la chaleur, Gauthier-Villars, Paris, 665 pp., 1903.

Crespo, A. J. C., Gomez-Gesteira, M., and Dalrymple, R. A.: Modeling dam break behavior over a wet bed by a SPH technique, J. Waterw. Port C-ASCE, 134(6), 313-320, 2008.

De Maio, A., Savi, F., and Sclafani, L: Three-dimensional Mathematical Simulation of Dambreak Flow. Proceeding of IASTED conferences - Environmental Modelling and Simulation ISBN: 0-88986-441-1 St. Thomas, US Virgin Island, 2004.

Faber, T. E.: Fluid dynamics for physicists, Cambridge University Press, 470 pp., 1995.

Fennema, R. J. and Chaudhry, M. H.: Explicit methods for twodimensional transient free-surface flows, JHE, 116(8), 10131034, 1990.

Fraccarollo, L. and Toro, E. F.: Experimental and numerical assessment of the shallow water model for two-dimensional dam-break problems, J. Hydr. Res., 33, 843-864, 1995.

Fread, D. L., Flow Routing in Handbook of Hydrology, edited by: Maidment, D. R., McGraw-Hill Inc., New York, USA, 10.110.36, 1993.

Galperin, B., Orszag, S. A. (Eds.): Large Eddy Simulation of Complex Engineering and Geophysical Flows, Cambridge University Press, 622 pp., 1993.

Gómez-Gesteira, M. and Dalrymple, R. A.: Using a threedimensional smoothed particle hydrodynamics method for wave impact on a tall structure, J. Waterway, Port, Coastal and Ocean Eng., 130(2), 63-69, 2004.

Hirsch, C.: Numerical Computation of Internal and External Flows, John Wiley \& Sons, 515 pp., 1992.
Hromadka, T. V., Berenbrock, C. E., Freckleton, J. R., and Guymon, G. L.: A two-dimensional dam-break flood plain model, Adv. Wat. Res., 8, 7-14 March, 1985.

Issa, R. I.: Solution of the implicitly discretised fluid flow equations by operator-splitting, J. Comput. Phys., 62(1), 40-65, 1986.

Jasak, H. G.: Error Analysis and Estimation for the Finite Volume Method with Application to Fluid Flows, $\mathrm{PhD}$ thesis, Imperial College of Science, Technology and Medicine, 1996

Jia, Y. and Wang, S. S. Y.: Two-dimensional Hydrodynamic and Sediment Transport Model for Unsteady Open Channel Flow Over Loose Bed, 2001 - Tech. Rep. NCCHE-TR2001-01, NCCHE, 2001.

Jia, Y., and Wang, S. S. Y,: Numerical Model for Channel Flow and Morphological Change Studies, J. Hydraul. Eng.-Asce., 125, 924-933, 1999.

Jorgenson, J., Xinya, Y., and Woodman, W.: Two-dimensional modeling of dam breach flooding, US-China workshop on advanced computational modelling in hydroscience \& engineering, 19-21 September, Oxford, Mississippi, USA, 2004.

Liang, D., Lin, B., and Falconer, R. A.: Simulation of rapidly varying flow using an efficient TVD-MacCormack scheme, Int. J. Numer. Meth. Fl., 53, 811-826, 2007.

Liu, X. and García, M. H.: A three-dimensional Numerical Model with Free Water Surface and Mesh Deformation for Local Sediment Scour, J. Waterw., Port, Coastal, and Ocean Engineering, 134(4), 203-217, 2008.

Manciola, P., Mazzoni, A., and Savi, F.: Formation and Propagation of Steep Waves: An Investigative Experimental Interpretation, Proceedings of the Specialty Conference Co-sponsored by ASCE-CNR/CNDCI-ENEL spa held in Milan, Italy, 29 June-1 July, 1994.

Mohammadi, M.: Boundary shear stress around bridge piers, Am. J. Appl. Sci., 5(11), 1547-1551, November, 2008.

Mohapatra, P. K., Eswaran, V., and Bhallamudi, S. M.: Twodimensional analysis of dam-break flow in vertical plane, J. Hydr. Engng. ASCE, 125(2), 183-192, 1999.

Morris, M. W. and Gallnd, J. C.: Dam Break modelling Guidelines $\&$ Best Practice (2000) Final Report CADAM concerted Action on dam break modelling, HR Wallingford, 2000.

Nagata, N., Hosoda, T., Nakato, T., and Muramoto, Y.: ThreeDimensional Numerical Model for Flow and Bed Deformation around River Hydraulic, J. Hydraul. Eng.-ASCE, 131(12), 10741087, 2005.

Open FOAM, The Open Source CFD Toolbox, User Guide, Version 1.5, 9 July, 2008.

Patankar, S. V.: Numerical Heat Transfer and Fluid Flow, McGrawHill, 197 pp., 1981.

Quecedo, M., Pastor, M., Herreros, M.I., Fernandez Merodo, J. A., and Zhang, Q.: Comparison of two mathematical models for solving the dam break problem using the FEM method, Comput. Method Appl. M., 194(36-38), 3984-4005, 2005.

Rodi, W.: Turbulence Models and Their Application in Hydraulics, IAHR, State of Art Paper, IAHR section on Fundamental of Division II: experimental and mathematical fluid dynamics, 104 pp., 1979.

Soares Frazão, S.: Dam-break induced flows in complex topographies. Theoretical, numerical and experimental approaches, $\mathrm{PhD}$ Thesis, Louvain-la-Neuve: Università catholique de Louvain, Civil Engineering Department, Hydraulics Division, 116(8), 
2002.

Soarez Frazão, S. and Zech, Y.: Dam Break in channels with $90^{\circ}$ bend, J. Hydraul. Eng.-ASCE, 128(11), 956-968, 2002.

Tossou, E. E.: Extension of the 2 DH Saint-Venant hydrodynamic model for flows with vertical acceleration, $\mathrm{PhD}$ Thesis Université Laval Pav, Jean-Charles-Bonenfant Bibliothèque des sciences humaines et sociales Thèses et livres rares, 2009.

Ubbink, O. and Issa, R. I.: A method for capturing sharp fluid interfaces on arbitrary meshes, Journal of Computatonal Physics, 153, 26-50, 1999.

Wang, J. S., Ni, H. G., He, Y. S.:: He Finite-Difference TVD Scheme for Computation of Dam-Break Problems, Journal of Hydraulic Engineering-Reston, American Society of Civil Engineers, 2000.
Wang, S. S. Y. and Hu, K. K.: Improved methodology for formulating finite-element hydrodynamic models, in: Finite Element in Fluids, edited by : Chung, T. J., Hemisphere Publication Cooperation, 8, 457-478, 1992.

Weller, H. G., Tabor, G., Jasak, H., and Fureby, C.: A tensorial approach to computational continuum mechanics using objectoriented techniques, Comput. Phys., 12(6), 620-631, 1998.

Werner, M. G. F.: A comparison of flood extent modelling approaches through constraining uncertainties on gauge data, Hydrol. Earth Syst. Sci., 8, 1141-1152, 2004, http://www.hydrol-earth-syst-sci.net/8/1141/2004/.

Whitham, G. B.: Linear and Nonlinear Waves, Wiley, 635 pp., 1974.

Xanthopoulos, T. and Koutitas, C.: Numerical simulation of a twodimensional flood wave propagation due to dam-failure, J. Hyd. Res., 14, 4, 321-331, 1976. 